\title{
Impact of Different Parameters upon the Production of Virulence Factors in Escherichia coli Strains Isolated from Marine Water
}

\author{
Emilia Panus 1, Mariana Carmen Chifiriuc 2(D), Coralia Bleotu ${ }^{3}$, Corneliu Ovidiu Vrancianu 2,*(D), \\ Gratiela Gradisteanu ${ }^{2}$, Natalia Rosoiu 4,5 (D) \\ 1 Institute of Public Health, Constanta \\ 2 University of Bucharest, Faculty of Biology, Microbiology-Immunology Department and the Research Institute of the \\ University of Bucharest, Romania \\ 3 Institute of Virology St.Nicolau, Bucharest, Romania \\ 4 Ovidiu's University Faculty of Medicine, Department of Biochemistry, Constanta, Romania \\ 5 Academy of Romanian Scientists 54 Splaiul Independentei 050094, Constanta \\ * Correspondence: ovidiu.vrancianu@yahoo.com;
}

Scopus Author ID 57216898828

Received: 2.05.2020; Revised: 27.05.2020; Accepted: 28.05.2020; Published: 1.06.2020

\begin{abstract}
This study aimed to look into the expression of 10 virulence factors (VF) in 100 Escherichia coli strains harvested from the Black Sea Coast. E. coli strains were grown under different conditions, simulating various environmental stressors. The VF production [esculinase, amylase, pore-forming enzymes (hemolysin - spot and CAMP-like hemolysis; lipase; lecithinase)], lysine-decarboxylase, proteases (caseinase, gelatinase) and DNase was investigated at variable temperatures $\left(4^{\circ} \mathrm{C}, 22^{\circ} \mathrm{C}\right.$, $37^{\circ} \mathrm{C}, 44^{\circ} \mathrm{C}$ and $56^{\circ} \mathrm{C}$ ), $\mathrm{NaCl}$ (from 0 to $10 \%$ ) and glucose concentrations ( $1.5 \%$ and $3 \%$ ), different $\mathrm{pH}$ values (5.0, 7.2 and 9.6) and also in aerobic or anaerobic incubation conditions. The investigation of $E$. coli strains unraveled their ability to grow at $22^{\circ} \mathrm{C}, 37^{\circ} \mathrm{C}, 44^{\circ} \mathrm{C}$, regardless of the salinity, $\mathrm{pH}$, and glucose concentration, both in aerobic and anaerobic incubation conditions. The VF were better expressed at $37^{\circ} \mathrm{C}$, followed by $22^{\circ} \mathrm{C}$, especially siderophores, amylase, and caseinase production. The expression of different VF was variable at a certain salinity, i.e., at $0 \% \mathrm{NaCl}$, only amylase and siderophores production was observed. At $2 \%$ and $3 \%$, the amylase was better expressed. The best expression of siderophores and caseinase was at $6 \% \mathrm{NaCl}$. At higher salinity, the expression of $\mathrm{VF}$ started to decrease. The amylase and caseinase were better expressed at $\mathrm{pH} 9.6$ and siderophores at $\mathrm{pH}$ 7.2. Higher glucose concentrations (3\%) proved to have an inhibitory effect on amylase expression and caseinase. The aerobic/anaerobic incubation conditions exhibited no significant differences in the VF expression. In conclusion, these outcomes reveal the ability of enterobacterial aquatic strains to survive in the presence of different stressors and maintain the expression of potential VF expression even in extreme environmental conditions.
\end{abstract}

Keywords: Escherichia coli; virulence factors; physico-chemical stressors.

(C) 2020 by the authors. This article is an open-access article distributed under the terms and conditions of the Creative Commons Attribution (CC BY) license (https://creativecommons.org/licenses/by/4.0/).

\section{Introduction}

Fecal pollution of water bodies is a challenging concern both in the environment and public health [1]. Fecal pollution may occur from different sources, including wastewater, agricultural, and urban pluvial spills [2]. Identifying and eliminating the cause of contamination is not an easy task. In the main, measuring the density of fecal indicators for evaluating fecal pollution involves a limited number of surface water samples $[3,4]$. 
E. coli is a fecal coliform bacteria that can be found in the animal and human intestine [5]. The identification of $E$. coli in the water is a characteristic indicator of recent pollution with animal dejection or wastewaters [6,7]. During various precipitations such as rains or melting snow, these bacteria can be lugged in bays, rivers, lakes, or groundwater. If these contaminated waters are not treated or inadequately treated, using them as drinking water can lead to an infection with this bacteria [8,9]. E. coli can survive in benthos and afterward can pass in surface waters [10]. At low temperatures, residual pollution can still be observed, even the levels of fecal coliform rapidly decrease. However, a restoration between $1 \%$ to $10 \%$ of the total initial population can be observed subsequently. Furthermore, it was observed that $E$. coli strains collected from septic tanks have low genetic variability, forming a distinct clone [11]. This is in contrast to E. coli strains isolated from the water tanks of households [12].

Most $E$. coli strains from water flows are nonpathogenic and live in healthy human and animal intestines. However, there are still some E. coli strains that may express VF acquired from pathogenic species, factors that can lead to the occurrence of severe clinical forms of infection [13-19].

\section{Materials and Methods}

In this study, were have analyzed the VF profiles $100 \mathrm{E}$. coli strains collected in Constanta, Romania, from seawater. The isolation of these strains was realized using the filter membrane method, according to SR ISO 9308-1 2000, using a volume of $100 \mathrm{ml}$ water and a filter membrane with a $47 \mathrm{~mm}$ diameter. Afterward, the membrane is placed over Lactose TTC medium discharged in $47 \mathrm{~mm}$ diameter Petri plates. Subsequently, at the end of 48 hours incubation at $44^{\circ} \mathrm{C}, E$. coli yellow colonies will be further identified by oxidase and indole production tests.

Inoculation of $1 \mathrm{~mL}$ broth was realized using bacterial suspensions performed in PBS from $24 \mathrm{~h}$ cultures, with $0.5 \mathrm{McFarland}$ standard turbidity. Afterward, the media were incubated $24 \mathrm{~h}$ at different temperatures $\left(4^{\circ} \mathrm{C}, 22^{\circ} \mathrm{C}, 37^{\circ} \mathrm{C}, 44^{\circ} \mathrm{C}\right.$, and $\left.56^{\circ} \mathrm{C}\right)$, both in aerobic and anaerobic conditions. Subsequently, the same suspensions were used for inoculation of $1 \mathrm{ml}$ broth with different $\mathrm{pH}$ values $(5.0,7.2$ and 9.6), glucose $(1.5 \%$ and $3 \%)$ and $\mathrm{NaCl}$ concentrations $(0 \%$, $0.5 \%, 2 \%, 3 \%, 4 \%, 5 \%, 6 \%, 7 \%$, and $10 \%$ ). After $24 \mathrm{~h}$ at $37^{\circ} \mathrm{C}$ expression of soluble VF (i.e., lecithinase, lipase, hemolysin - spot and CAMP-like hemolysis, gelatinase, caseinase, amylase, siderophores production, DN-ase, lyzindecarboxylase) of the E. coli strains grown in different stress conditions were investigated [20]. Detection of the pore forming-toxins was done by spotting the cultures on $1 \%$ Tween 80 agar for lipase and $2.5 \%$ yolk agar for lecithinase and incubated up to seven days at $37^{\circ} \mathrm{C}$. An opaque (precipitation) region around the spot was confirmed as a positive reaction for lipase and lecithinase production [21]. Isolated colonies were obtained streaking E. coli strains on blood agar plates containing $5 \%$ (vol/vol) sheep blood, followed by incubation $24 \mathrm{~h}$ at $37^{\circ} \mathrm{C}$. In the end, the clear regions (lysis of red blood cells) around the colonies were confirmed as positive reactions. To test the production of the CAMP-like factor, the strains were streaked at $8 \mathrm{~mm}$ distance from the $\beta$-hemolysis, producing Staphylococcus aureus (ATTC25923) and Rhodococcus equi (ATCC 6939) strain on 5\% sheep blood agar plates and incubated in aerobic conditions at $37^{\circ} \mathrm{C}$ for $24 \mathrm{~h}$. The synthesis of the CAMP-like factor was confirmed by synergistic clear hemolysis observed at the junction of the two spots areas, often with an arrow-like shape [22]. 
To investigate gelatinase production, the strains were spotted in the solid medium and incubated with gelatin $37^{\circ} \mathrm{C}$ for $24 \mathrm{~h}$. The presence of an area of precipitation around the area of growth indicated proteolysis of gelatine (presence of gelatinase).

The caseinase activity was established using a $15 \%$ soluble casein agar as a substrate. After spotting and incubation of strains at $37^{\circ} \mathrm{C}$ for $24 \mathrm{~h}$, a clearing zone surrounding the growth indicated casein proteolysis.

Amylase production was tested on a $10 \%$ starch supplemented agar medium. The strains were streaked and incubated at $37^{\circ} \mathrm{C}$ for $24 \mathrm{~h}$. Starch hydrolysis was confirmed through a transparent region around the culture spot.

The siderophores production was tested by the esculin hydrolysis reaction. For this purpose, the strains have been streaked on esculin. Esculin reacts with Fe citrate from medium, and subsequently, the esculetol (acting as siderophore production) was indicated by the occurrence of black color, highlighting the ability of bacteria to hydrolyze esculin.

The DNase production was observed using a DNA supplemented medium. On this medium, E. coli strains were spotted and incubated at $37^{\circ} \mathrm{C}$ for $24 \mathrm{~h}$. Following incubation, upon the spotted cultures was added a drop of $\mathrm{HCl} 1 \mathrm{~N}$ solution, and the clear regions around the culture were registered as positive reactions.

Decarboxilases (LDC) have a good activity (efficiency) in anaerobiotic conditions and acid $\mathrm{pH}$. This enzyme has the ability to catalyze in the presence of phosphate pyridoxal coenzyme and ornithine (diamino-monocarboxylic amino acids). Lysine-decarboxylase reaction involves specific diamines production [23,24]. Lysine decarboxylase detection is realized based on highlighting the $\mathrm{pH}$ variation in the environment. The glucose fermentation in bacteria with fermentative metabolism can be observed by growing on acid medium, whose color will change from purple to yellow. When bacteria do not harbor the enzymatic equipment to produce lysine decarboxylase, the medium remains purple. In the presence of enzymes like phosphate pyridoxal coenzyme and ornithine (diamino-monocarboxylic amino acids), a secondary re-alkalinization of the medium due to diamine-cadaverine production will have a place. The medium color will turn again to purple [25,26].

\section{Results and Discussion}

The physical and chemical environmental conditions firmly influence the optimal biological activity of microorganisms. Both the growth and multiplication processes will typically take place only if the environmental conditions are optimal. In natural environments, optimal conditions are infrequent, but bacteria can manage this through a remarkable ability to adapt and survive in extreme conditions [27,28].

As shown in figures 1 and 2, of the 11 soluble VF tested, 8 of them expressed high levels; the highest level of expression was noticed for amylase when we used a liquid medium for obtaining primary cultures.

These results demonstrate that both the capacity of invasion and the toxigenesis in marine E. coli strains are much better expressed when the bacteria are developed in a liquid medium.

Temperature is an essential factor that influences several processes like biochemical reactions in cells, increasing proportionally, and the ability to survive. Nucleic acids and other cellular components are sensitive to high temperatures above a certain level and can be irreversibly inactivated. Unlike the extreme temperatures that could block the antimicrobial activity, moderate temperatures tolerate the normal metabolic processes [29, 30]. 


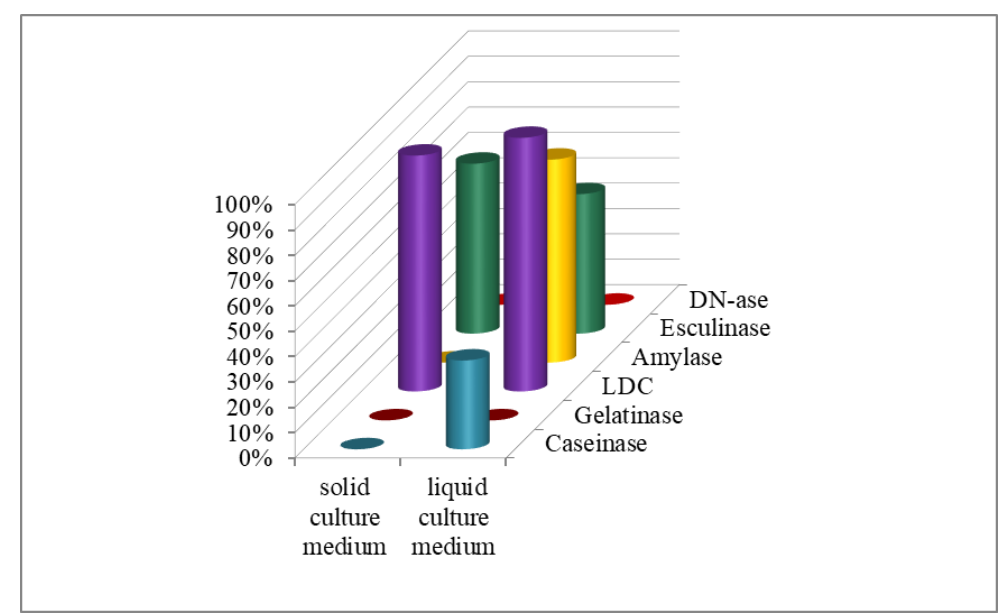

Figure 1. The influence of the consistency of the culture medium on the level of the phenotypic expression (\%) of the enzymes with role in the process of invasion and survival in E. coli strains harvested from seawater, incubated in aerobiosis.

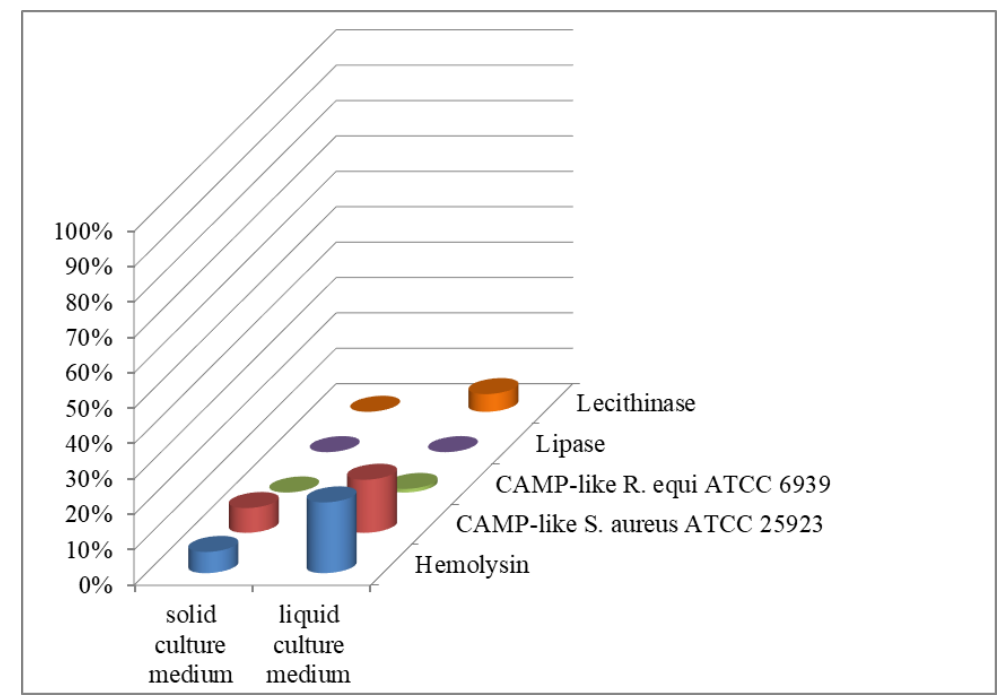

Figure 2 . The influence of the consistency of the culture medium on the level of the phenotypic expression (\%) of the pore-forming toxins in E. coli strains obtained from seawater, incubated in anaerobiosis.

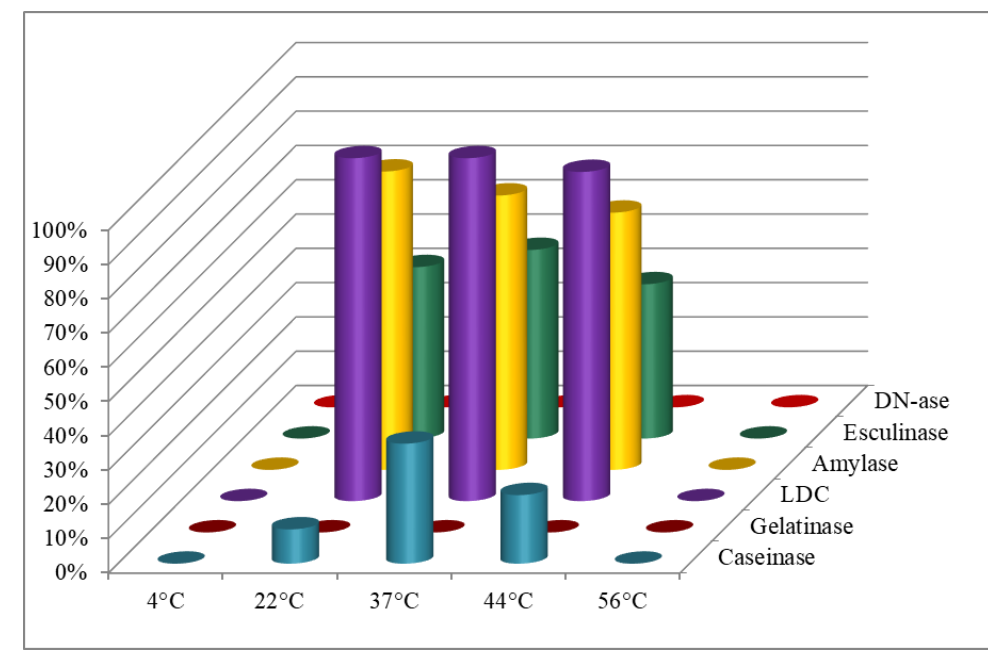

Figure 3. The influence of temperature in aerobiosis conditions on the level of the phenotypic expression (\%) of the enzymes involved in the process of invasion and survival in E. coli strains harvested from seawater. 


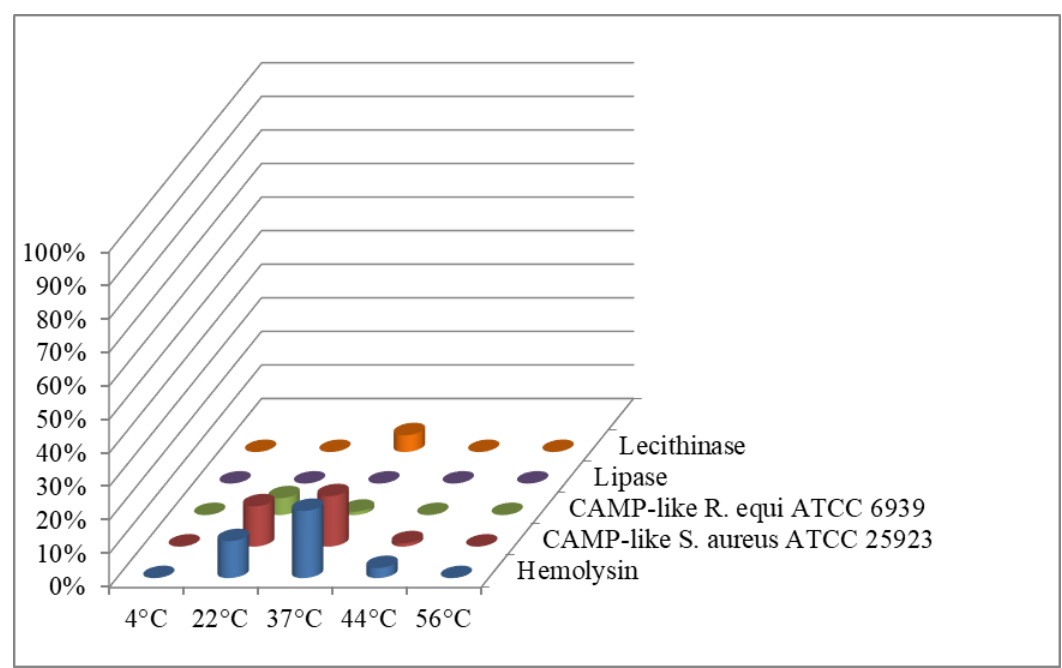

Figure 4. The influence of temperature on the level of the phenotypic expression (\%) of the pore forming toxins in $E$. coli strains isolated from seawater incubated in aerobiosis.

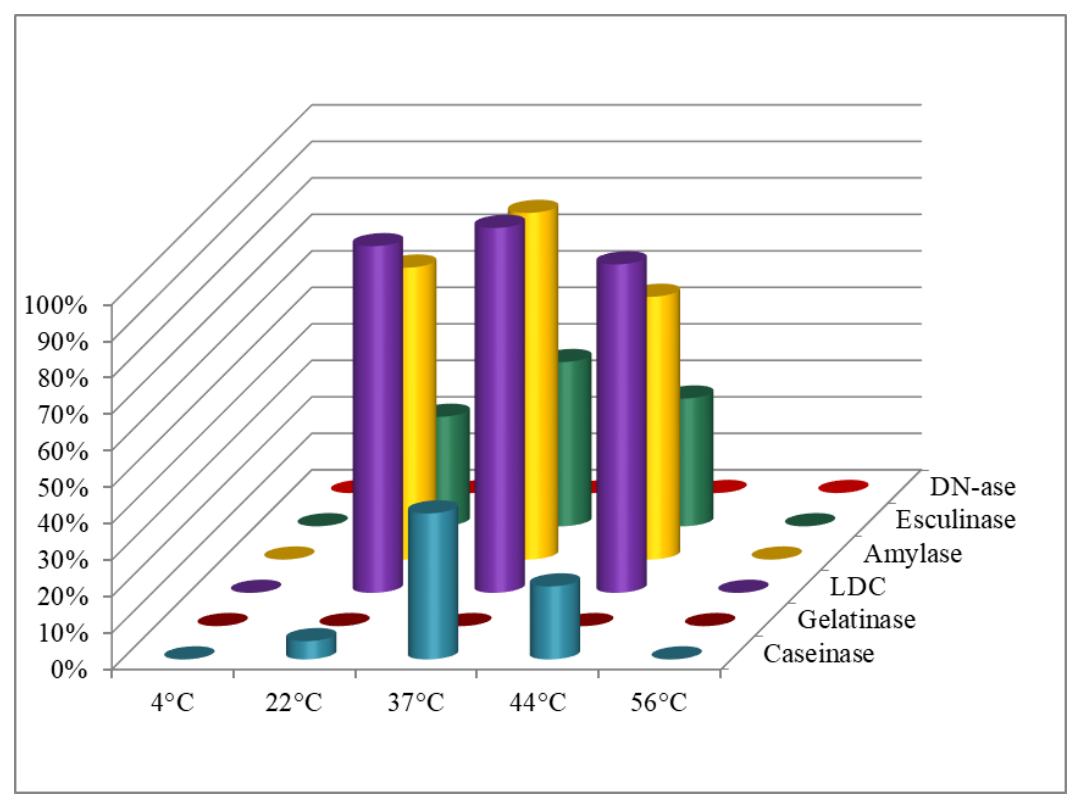

Figure 5. The influence of temperature on the level of the phenotypic expression (\%) of the enzymes involved in the process of invasion and survival in E. coli strains incubated in anaerobiosis.

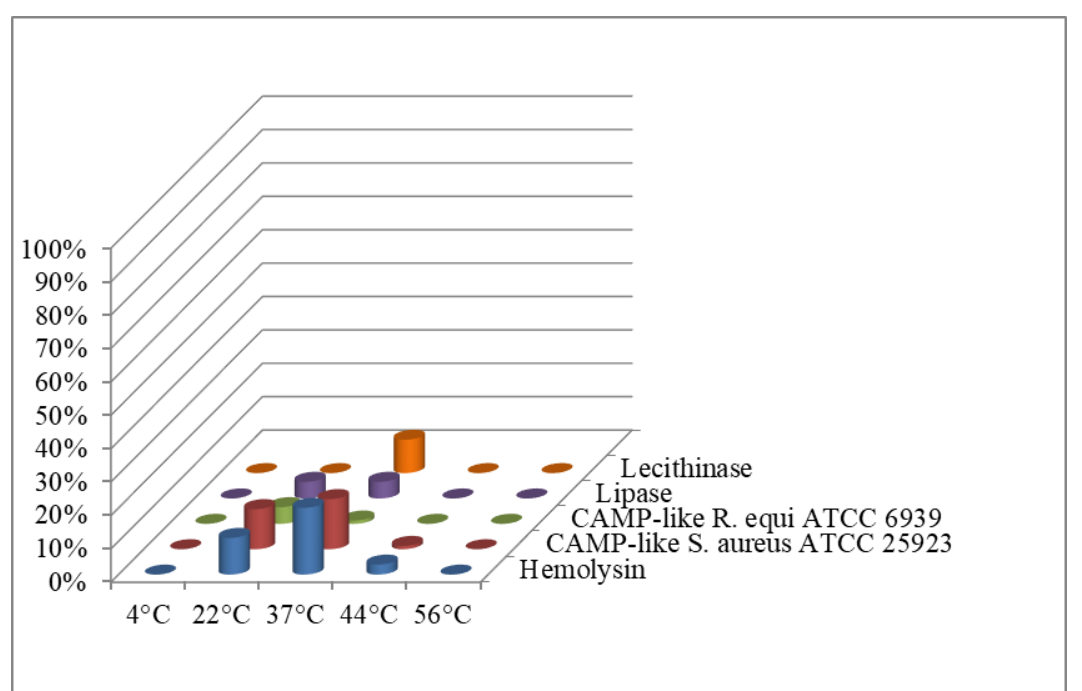

Figure 6. The impact of temperature on the level of the phenotypic expression (\%) of the pore-forming toxins in $E$. coli strains incubated in anaerobiosis. 
In terms of incubation temperature, the broadest spectrum of virulence expression factors was observed at $37^{\circ} \mathrm{C}$, in strains incubated in anaerobe conditions (fig. 3, 4). These results could explain the pathogenicity of $E$. coli strains involved in intra-abdominal infections.

Similarly, in anaerobiosis conditions, at $37^{\circ} \mathrm{C}$, the expression of the most soluble VF was observed for both the enzymes involved in the invasion and survival, as well as in the poreforming processes (fig. 5, 6).

The expression of the enzymes involved in the invasion and survival process is slightly inhibited in anaerobiosis conditions, regardless of the incubation temperature (fig. 7,8).

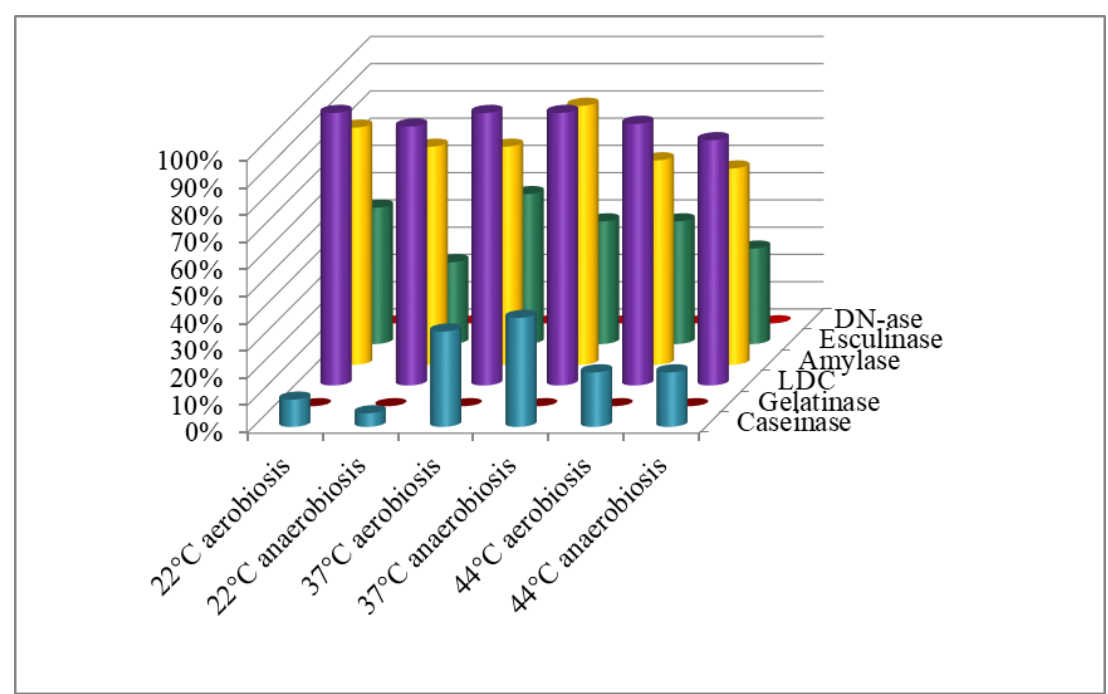

Figure 7. The consequence of $\mathrm{O}_{2}$ presence/absence on the level of the phenotypic expression (\%) of the enzymes involved in the process of invasion and survival in E. coli strains.

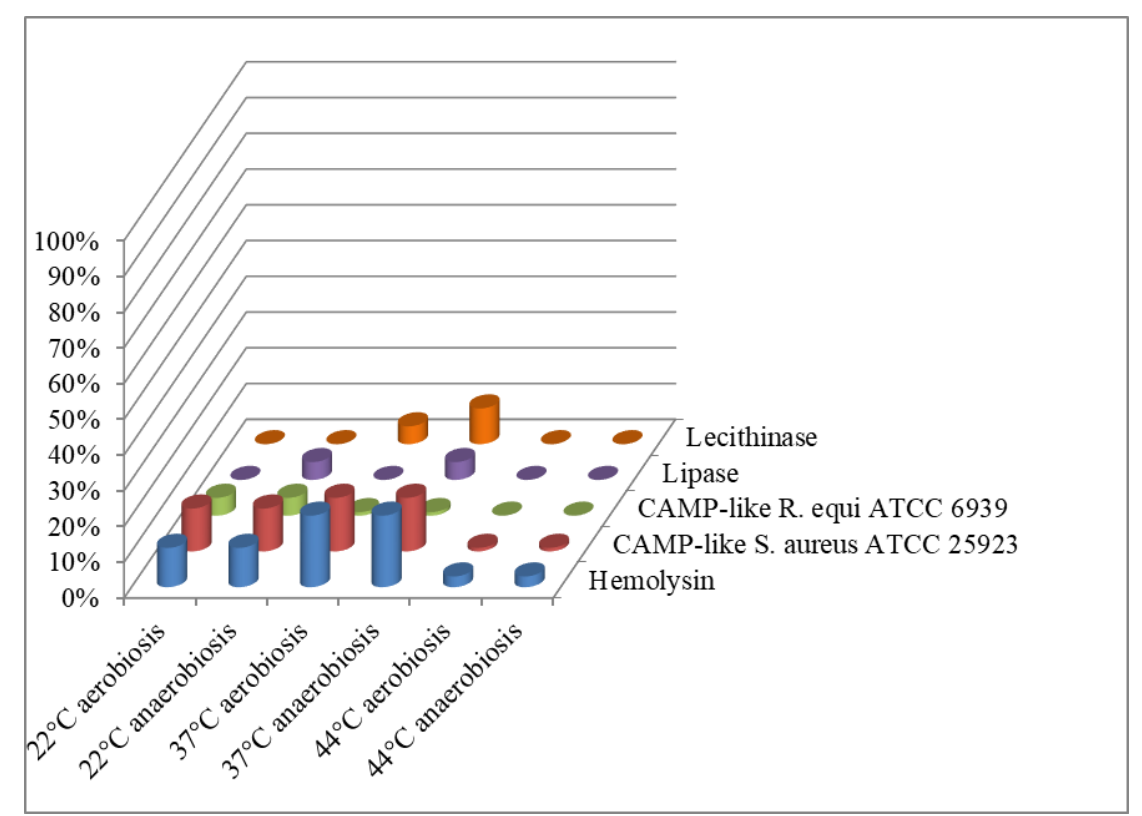

Figure 8. The impact of $\mathrm{O}_{2}$ presence/absence on the level of the phenotypic expression (\%) of the pore-forming toxins in E. coli strains.

Each microbial species grows at optimum $\mathrm{pH}$, mostly at a neutral one (7.2 to 7.6), excepting Vibrio cholerae that grow at an alkaline $\mathrm{pH}$ (8.9 to 9.2). At the same time, yeasts and molds survive in acid $\mathrm{pH}$ [31].

The lecithinase was slightly expressed only in physiological $\mathrm{pH}$ (7.2); this also is the $\mathrm{pH}$ value at which the most soluble VF were expressed. The caseinase and amylase expression is favored by acid $\mathrm{pH}$. The lysine decarboxylase was the only enzyme on which the $\mathrm{pH}$ 
variation of the culture medium did not modify, expressing in $100 \%$ in all $\mathrm{pH}$ variations (fig. $9,10)$. The $\mathrm{pH}$ variation did not significantly influence the expression of the VF, who presented a similar profile, with a remarkable growth of the proteolytic potential, emphasized by the high level of caseinase in pH 5.0 (fig. 9, 10).

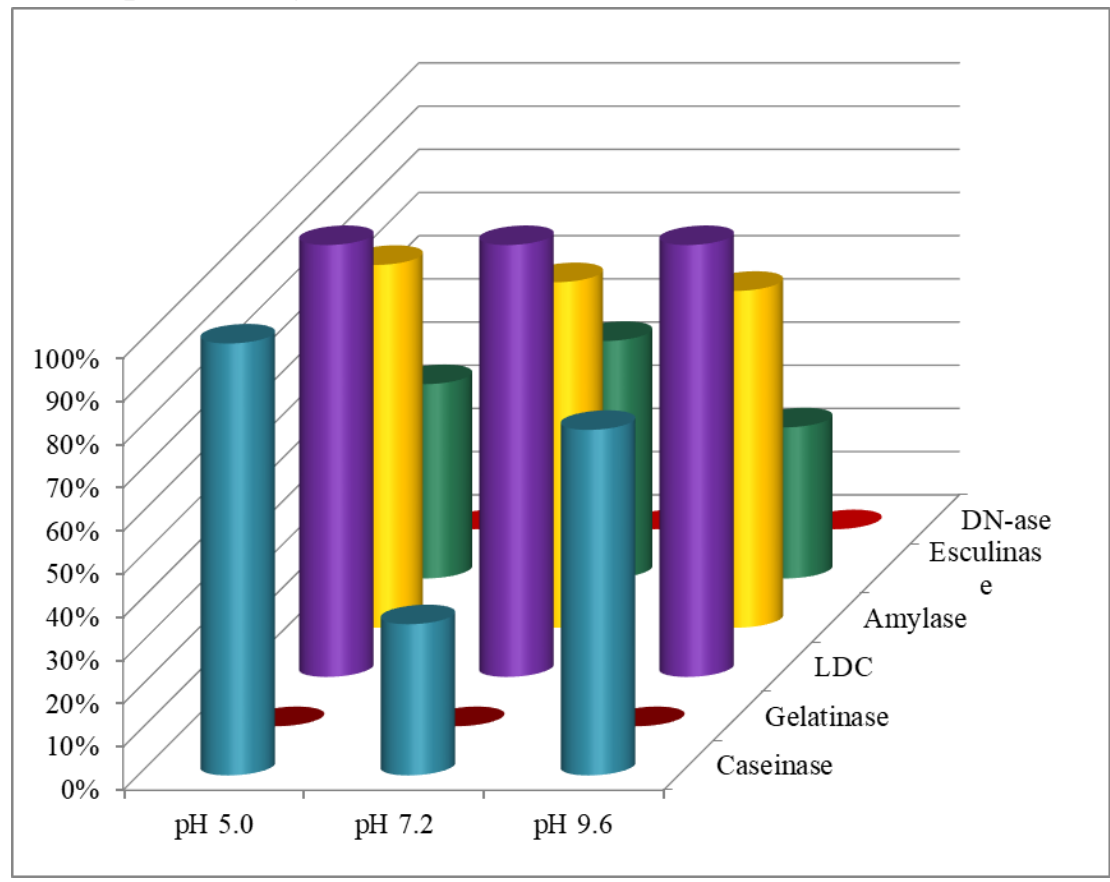

Figure 9. The impact of the culture medium's pH variation on the level of the phenotypic expression (\%) of the enzymes involved in the invasion and survival capacity of E. coli strains harvested from seawater.

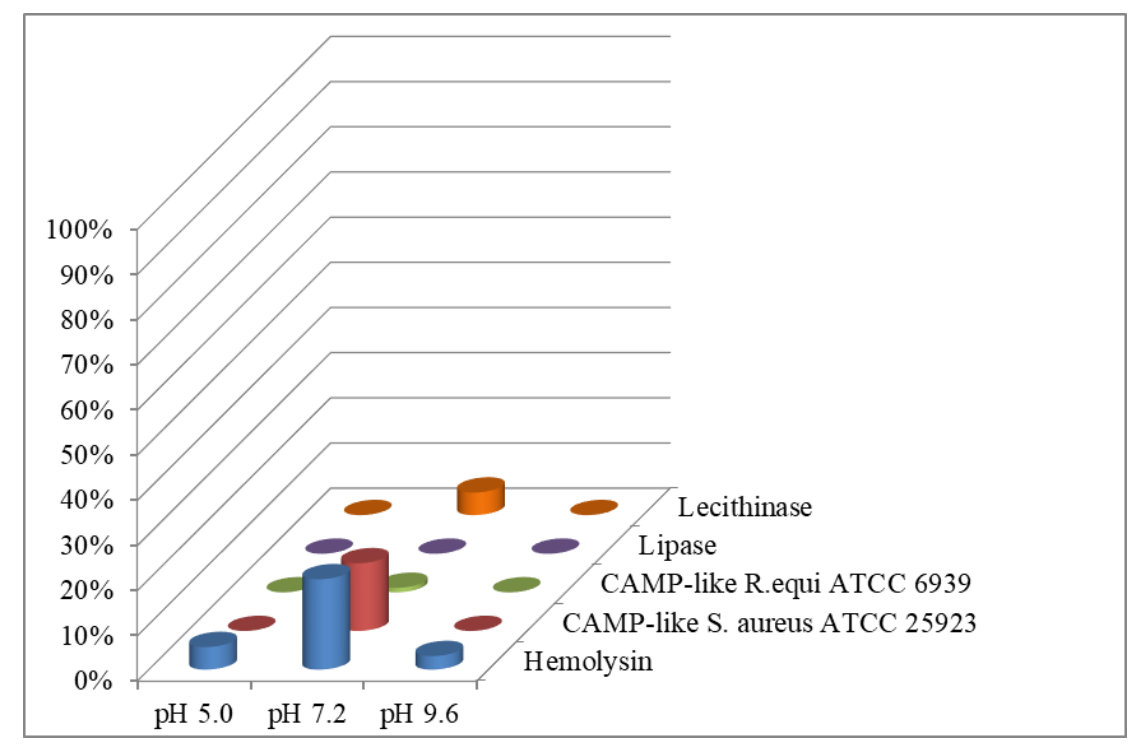

Figure 10. The consequence of the $\mathrm{pH}$ variation on the level of the phenotypic expression (\%) of the poreforming toxins in E. coli strains isolated from seawater.

This study has found that soluble VF were better expressed in lower glucose concentrations $(1.5 \%)$ (fig. 11,12$)$.

The higher glucose concentration (3\%) in the medium slightly inhibited the expression of lysine decarboxylase, amylase (fig. 11), hemolysin, and of the CAMP factor with S. aureus ATCC 25923 (fig. 12). This glucose concentration from the culture medium induced significant influences in the expression of esculinase (fig. 13) and caseinase (fig. 11).

The $1.5 \%$ glucose concentration stimulated the esculinase production (fig. 13), demonstrating the fact that at a low glucose concentration, bacteria synthesize enzymes 
involved in metabolizing other $\mathrm{C}$ sources, like the case of esculin, a complex heteroside, revealing the ability of these strains to initiate an infectious process.

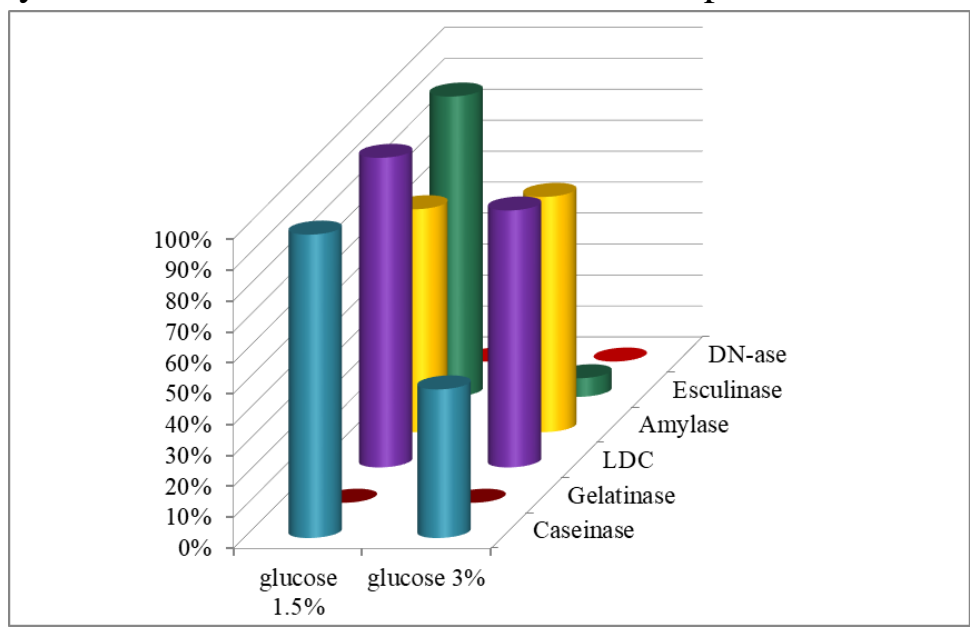

Figure 11. The impact of the glucose concentration on the level of the phenotypic expression (\%) of the enzymes involved in the invasion and survival in E. coli strains.

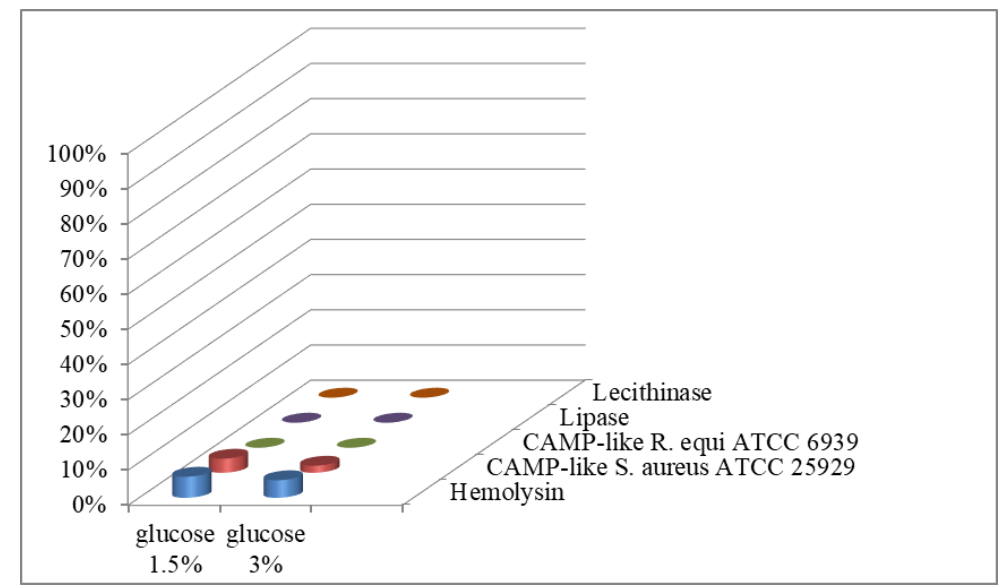

Figure 12. The effects of the glucose concentration on the level of the phenotypic expression (\%) of the pore-forming toxins in E. coli strains.

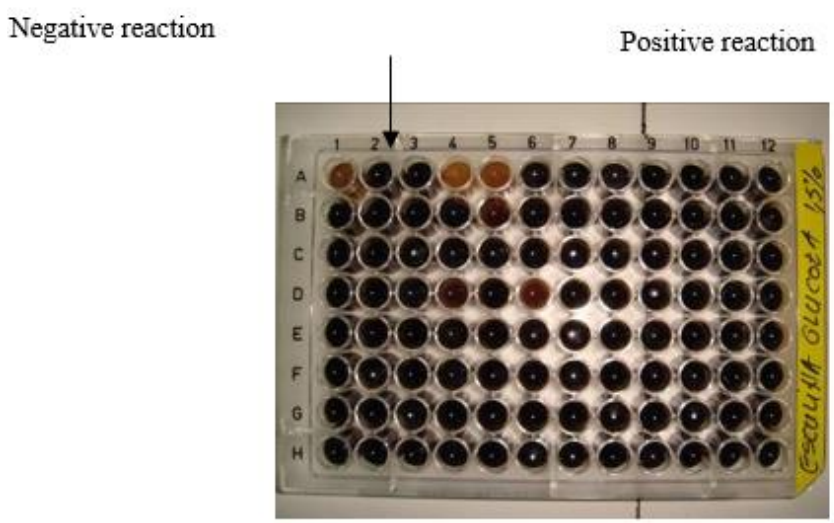

a. the expression of esculinase in the presence of $1.5 \%$ glucose concentration

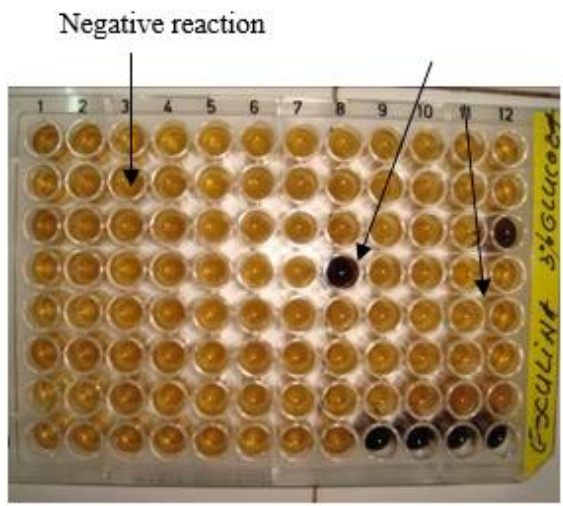

b. the expression of esculinase in the presence of $3 \%$ glucose concentration

Figure 13. The impact of the glucose concentration on the expression of esculinase in $E$. coli strains isolated from seawater ( $a$ and $b)$. 
Different $\mathrm{NaCl}$ concentrations in the culture medium generally inhibited the expression of the soluble VF; the most significant percentage of soluble VF were expressed in $6 \%$ and $2 \%$ $\mathrm{NaCl}$ concentrations, followed by $0.5 \%$ (fig. 14, 15) [32].

It was observed that $\mathrm{NaCl}$ concentration has a substantial impact on the esculinase (fig. 16) and caseinase (fig. 14) expression.

In high $\mathrm{NaCl}$ concentrations in the culture medium, we observed a growth in the virulence potential, with a maximum value reached at $6 \% \mathrm{NaCl}$, demonstrating the fact that high osmolarity accentuates the potential of these strains to initiate an infectious process.

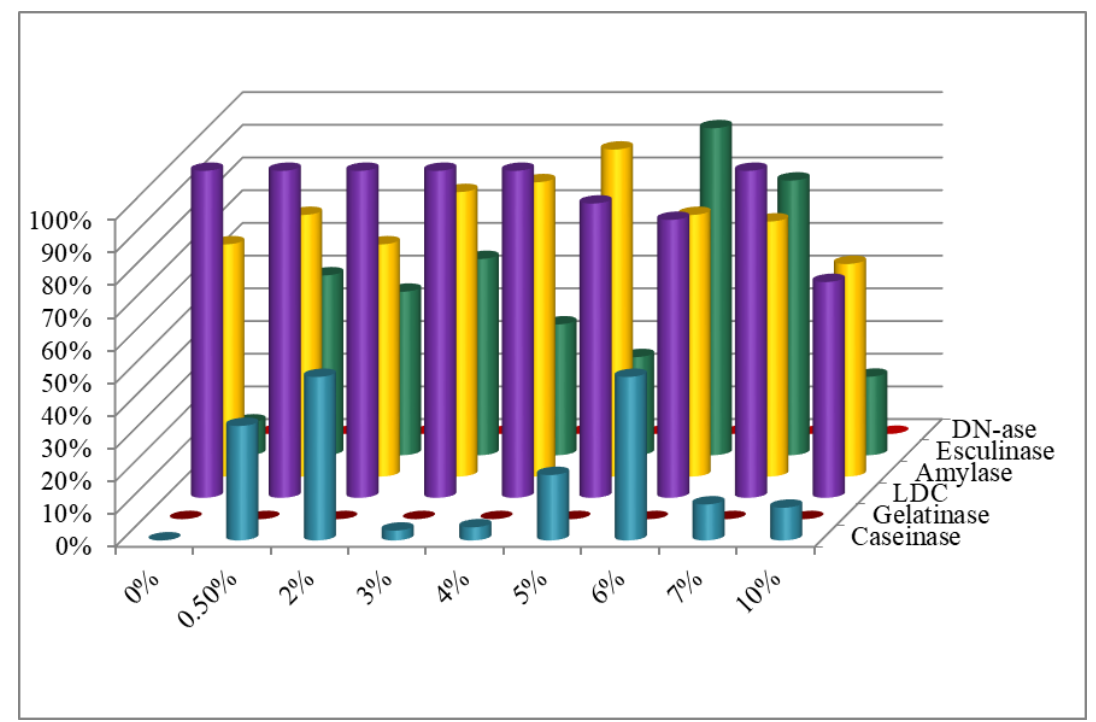

Figure 14. The impact of the $\mathrm{NaCl}$ concentration on the level of the phenotypic expression (\%) of the enzymes involved in the invasion and survival in E. coli strains.

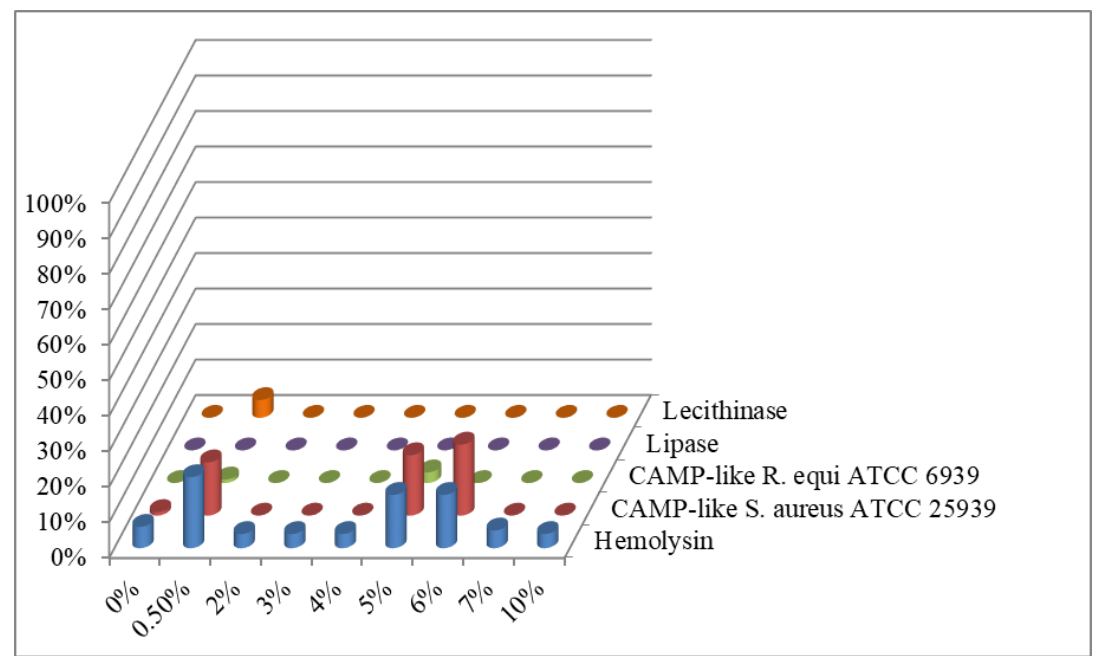

Figure 15. The effects of the $\mathrm{NaCl}$ concentration on the level of the phenotypic expression (\%) of the poreforming toxins in E. coli strains isolated from seawater.

Of the ten analyzed soluble VF, only amylase, esculinase, caseinase, lysinedecarboxylase, and hemolysins were expressed in all used $\mathrm{NaCl}$ concentrations, presenting different expression intensities.

The soluble VF with the most constant expression in different medium conditions were: amylase, esculinase, caseinase, lysine-decarboxylase, and hemolysins.

A slight expression was noticed for lecithinase and CAMP factor, both for S. aureus ATCC 25923, and for $R$. equi ATCC 6939, regardless of the incubation conditions. 
In the case of the present study, out of the ten soluble VF analyzed, two factors (lipase and DNase) were not highlighted in any of the cultivation conditions.

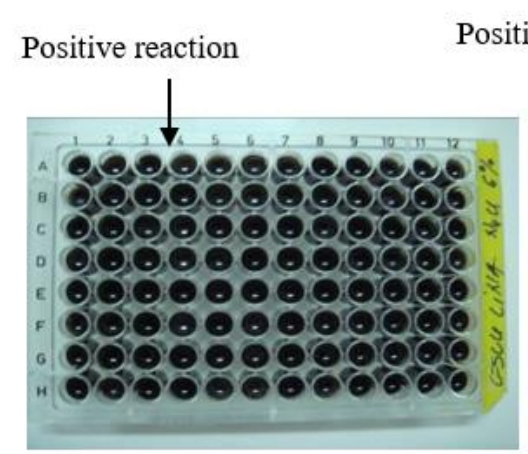

a. esculin hydrolysis in the presence of $6 \% \mathrm{NaCl}$ concentration

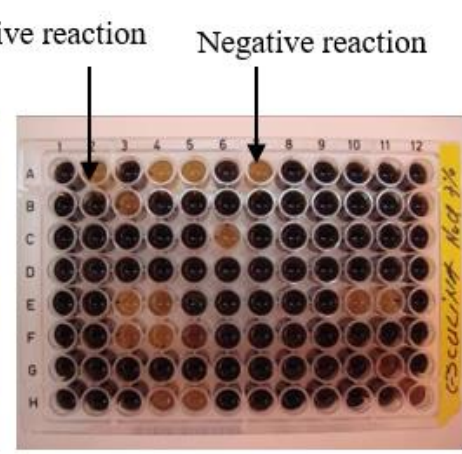

b. esculin hydrolysis in the presence of $7 \% \quad \mathrm{NaCl}$ concentration

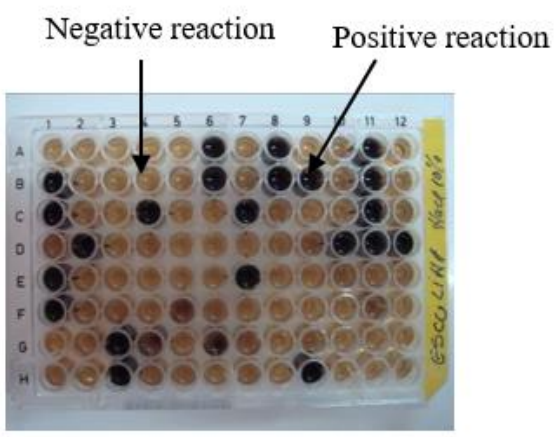

c. esculin hydrolysis in the presence of $10 \% \quad \mathrm{NaCl}$ concentration

Figure 16. The influence of the $\mathrm{NaCl}$ concentration on esculin hydrolysis capacity $(\mathrm{a}, \mathrm{b}$ and $\mathrm{c})$.

\section{Conclusions}

Among the tested VF, the most constant expression in different experimental conditions was obtained for lysine-decarboxylase, amylase, and hemolysin, and the largest variations for the production of esculetol (iron chelator) and caseinase. The highest expression of VF was noted at a temperature of $37^{\circ} \mathrm{C}, \mathrm{pH} 7.2,0.5 \% \mathrm{NaCl}$, and $1.5 \%$ glucose concentration. The incubation in aerobiosis/anaerobiosis did not influence the expression of VF. In all experimental conditions, it was observed that the enzymes with essential roles in the invasion and survival process were phenotypically expressed at higher levels, in contrast to the poreforming enzymes. Cultivation on liquid mediums favored the expression of enzymes for both the enzymes involved in the invasion and survival process and the pore-forming toxins.

\section{Funding}

The authors of this review have been supported by the Research Grant PN-III-P4-ID-PCCF-20160114, funded by the Executive Unit for Financing Higher Education, Research, Development, and Innovation (UEFISCDI).

\section{Acknowledgments}

This research has no acknowledgment.

\section{Conflicts of Interest}

The authors declare no conflict of interest.

\section{References}

1. Paruch, L.; Paruch, A.M.; Eiken, H.G.; Sørheim, R. Faecal Pollution Affects Abundance and Diversity of Aquatic Microbial Community in Anthropo-Zoogenically Influenced Lotic Ecosystems. Sci. Rep. 2019, 9 (1), 19469. https://doi.org/10.1038/s41598-019-56058-x.

2. Brooks, Y.M.; Spirito, C.M.; Bae, J.S.; Hong, A.; Mosier, E.M.; Sausele, D.J.; Fernandez-Baca, C.P.; Epstein, J.L.; Shapley, D.J.; Goodman, L.B.; Anderson, R.R.; Glaser, A.L.; Richardson, R.E. Fecal Indicator Bacteria, Fecal Source Tracking Markers, and Pathogens Detected in Two Hudson River Tributaries. Water 
Res. 2020, 171, 115342. https://doi.org/10.1016/j.watres.2019.115342.

3. Gordon, D.M.; Bauer, S.; Johnson, J.R. The Genetic Structure of Escherichia Coli Populations in Primary and Secondary Habitats. Microbiology 2002, 148 (Pt 5), 1513-1522. https://doi.org/10.1099/00221287-1485-1513.

4. $\quad$ Byappanahalli, M.; Fowler, M.; Shively, D.; Whitman, R. Ubiquity and Persistence of Escherichia Coli in a Midwestern Coastal Stream. Appl. Environ. Microbiol. 2003, 69 (8), 4549-4555. https://doi.org/10.1128/aem.69.8.4549-4555.2003.

5. Nielsen, K.L.; Dynesen, P.; Larsen, P.; Frimodt-Møller, N. Faecal Escherichia Coli from Patients with E. Coli Urinary Tract Infection and Healthy Controls Who Have Never Had a Urinary Tract Infection. J. Med. Microbiol. 2014, 63 (Pt 4), 582-589. https://doi.org/10.1099/jmm.0.068783-0.

6. Holcomb, D.A.; Knee, J.; Sumner, T.; Adriano, Z.; de Bruijn, E.; Nalá, R.; Cumming, O.; Brown, J.; Stewart, J.R. Human Fecal Contamination of Water, Soil, and Surfaces in Households Sharing Poor-Quality Sanitation Facilities in Maputo, Mozambique. Int. J. Hyg. Environ. Health 2020, 226, 113496. https://doi.org/10.1016/j.ijheh.2020.113496.

7. Senkbeil, J.K.; Ahmed, W.; Conrad, J.; Harwood, V.J. Use of Escherichia Coli Genes Associated with Human Sewage to Track Fecal Contamination Source in Subtropical Waters. Sci. Total Environ. 2019, 686, 1069-1075. https://doi.org/10.1016/j.scitotenv.2019.05.201.

8. Miloudi, S.; Chaib, M.; Ayat, M.; Rahmouni, A. Poly (Para-Acid Phenol-d-Glucose): Resin for the Removal of Fecal Coliforms and Escherichia Coli. Biointerface Res. Appl. Chem. 2018, 8, 3009-3015.

9. Llopis, F.; Grau, I.; Tubau, F.; Cisnal, M.; Pallares, R. Epidemiological and Clinical Characteristics of Bacteraemia Caused by Aeromonas Spp. as Compared with Escherichia Coli and Pseudomonas Aeruginosa. Scand. J. Infect. Dis. 2004, 36 (5), 335-341. https://doi.org/10.1080/00365540410020631.

10. Stocker, M.D.; Pachepsky, Y.A.; Hill, R.L.; Shelton, D.R. Depth-Dependent Survival of Escherichia Coli and Enterococci in Soil after Manure Application and Simulated Rainfall. Appl. Environ. Microbiol. 2015, 81 (14), 4801-4808. https://doi.org/10.1128/AEM.00705-15.

11. Khare, N.; Kaushik, M.; Kumar, S.; Gulati, P. Evaluation of Genetic Diversity among Aquatic and Fecal Isolates of Escherichia Coli Using Multilocus Variable Number of Tandem Repeat Analysis. 3 Biotech 2020, 10 (2), 63. https://doi.org/10.1007/s13205-020-2066-0.

12. McLellan, S.L. Genetic Diversity of Escherichia Coli Isolated from Urban Rivers and Beach Water. Appl. Environ. Microbiol. 2004, 70 (8), 4658-4665. https://doi.org/10.1128/AEM.70.8.4658-4665.2004.

13. Mosavie, M.; Blandy, O.; Jauneikaite, E.; Caldas, I.; Ellington, M.J.; Woodford, N.; Sriskandan, S. Sampling and Diversity of Escherichia Coli from the Enteric Microbiota in Patients with Escherichia Coli Bacteraemia. BMC Res. Notes 2019, 12 (1), 335. https://doi.org/10.1186/s13104-019-4369-y.

14. Singhal, N.; Sharma, D.; Kumar, M.; Bisht, D.; Virdi, J.S. Comparative Proteomics of Commensal and Pathogenic Strains of Escherichia Coli. Protein and peptide letters. Netherlands May 2020. https://doi.org/10.2174/0929866527666200517104154.

15. Düzgün, A.Ö.; Okumuş, F.; Saral, A.; Çiçek, A.Ç.; Cinemre, S. Determination of Antibiotic Resistance Genes and Virulence Factors in Escherichia Coli Isolated from Turkish Patients with Urinary Tract Infection. Rev. Soc. Bras. Med. Trop. 2019, 52, e20180499. https://doi.org/10.1590/0037-8682-0499-2018.

16. Porumbel, I.; Chelariu, M.; Gheorghe, I.; Curutiu, C.; Popa, M.; Delcaru, C.; Grosu, M.;Grigore, R.; Bertesteanu, S.; Lazar, V.; Vassu-Dimov, T. Genotypic characterization of virulence and resistance markers in ESBL positive Escherichia coli strains isolated from ambulatory urinary tract infections. Rom Biotechnol Lett. 2018, 23, 3: 13572-80

17. Kumar, P.A. Bacterial Resistance to Antimicrobial Agents and Microbiological Quality among Escherichia coli Isolated from Dry Fishes in Southeast Coast of India. Rom Biotechnol Lett, 2008, 13(6): 3984-3989

18. Selvamohan, T.; Palavesam, A.; Immanuel, G. Molecular Characterization of Escherichia coli isolated from estuarine environment bymultiplex PCR and RAPD analysis. Rom Biotechnol Lett. 2008, 13(2):1-5

19. Mladin, C.; Usein, C.R.; Chifiriuc, M.C.; Palade, A.; Slavu, C.L.; Negut, M.; Damian, M. Genetic analysis of virulence and pathogenicity features of uropathogenic Escherichia coli isolated from patietns with neurogenic bladder. Rom Biotechnol Lett., 2009, 14(6): 4900-4905.

20. Sarowska, J.; Futoma-Koloch, B.; Jama-Kmiecik, A.; Frej-Madrzak, M.; Ksiazczyk, M.; Bugla-Ploskonska, G.; Choroszy-Krol, I. Virulence Factors, Prevalence and Potential Transmission of Extraintestinal Pathogenic Escherichia Coli Isolated from Different Sources: Recent Reports. Gut Pathog. 2019, 11 (1), 10. https://doi.org/10.1186/s13099-019-0290-0.

21. Schwidder, M.; Heinisch, L.; Schmidt, H. Genetics, Toxicity, and Distribution of Enterohemorrhagic 
Escherichia Coli Hemolysin. Toxins (Basel). 2019, 11 (9). https://doi.org/10.3390/toxins11090502.

22. Litwin, C.M.; Johnson, J.M. Identification, Cloning, and Expression of the CAMP-like Factor Autotransporter Gene (Cfa) of Bartonella Henselae. Infect. Immun. 2005, 73 (7), 4205-4213. https://doi.org/10.1128/IAI.73.7.4205-4213.2005.

23. Shimizu, Y.; Rai, A.; Okawa, Y.; Tomatsu, H.; Sato, M.; Kera, K.; Suzuki, H.; Saito, K.; Yamazaki, M. Metabolic Diversification of Nitrogen-Containing Metabolites by the Expression of a Heterologous Lysine Decarboxylase Gene in Arabidopsis. Plant J. 2019, 100 (3), 505-521. https://doi.org/10.1111/tpj.14454.

24. Kandiah, E.; Carriel, D.; Garcia, P.S.; Felix, J.; Banzhaf, M.; Kritikos, G.; Bacia-Verloop, M.; BrochierArmanet, C.; Elsen, S.; Gutsche, I. Structure, Function, and Evolution of the Pseudomonas Aeruginosa Lysine Decarboxylase LdcA. Structure 2019, $27 \quad$ (12), $1842-1854 . e 4$. https://doi.org/10.1016/j.str.2019.10.003.

25. Kim, H.T.; Baritugo, K.-A.; Oh, Y.H.; Kang, K.-H.; Jung, Y.J.; Jang, S.; Song, B.K.; Kim, I.-K.; Lee, M.O.; Hwang, Y.T.; Park, K.; Park, S.J.; Joo, J.C. High-Level Conversion of 1-Lysine into Cadaverine by Escherichia Coli Whole Cell Biocatalyst Expressing Hafnia Alvei 1-Lysine Decarboxylase. Polymers (Basel). 2019, 11 (7). https://doi.org/10.3390/polym11071184.

26. Zhou, N.; Zhang, A.; Wei, G.; Yang, S.; Xu, S.; Chen, K.; Ouyang, P. Cadaverine Production From L-Lysine With Chitin-Binding Protein-Mediated Lysine Decarboxylase Immobilization. Front. Bioeng. Biotechnol. 2020, 8, 103. https://doi.org/10.3389/fbioe.2020.00103.

27. Bryan, G. A Guide to the Assessment of Heavy Metal Contamination in Estuaries Using Biological Indicators; Marine Biological Association of the United Kingdom, 1985.

28. Cardonha, A.M.S.; Vieira, R.H.S. dos F.; Peirano, G.; Rodrigues, D. dos P. [Resistance to antibiotics and heavy metals from Escherichia coli isolated from sea water and pluvial galeries]. Acta Cir. Bras. 2005, 20 Suppl 1, 253-256.

29. Barras, F.; Fontecave, M. Cobalt Stress in Escherichia Coli and Salmonella Enterica: Molecular Bases for Toxicity and Resistance. Metallomics 2011, 3 (11), 1130-1134. https://doi.org/10.1039/c1mt00099c.

30. Grijalva-Hernández, F.; Vega-Estrada, J.; Escobar-Rosales, M.; Ortega-López, J.; Aguilar-López, R.; Lara, A.R.; Montes-Horcasitas, M.D.C. High Kanamycin Concentration as Another Stress Factor Additional to Temperature to Increase PDNA Production in E. Coli DH5 $\alpha$ Batch and Fed-Batch Cultures. Microorganisms 2019, 7 (12). https://doi.org/10.3390/microorganisms7120711.

31. de Oliveira Coelho, B.; Fiorda-Mello, F.; de Melo Pereira, G. V; Thomaz-Soccol, V.; Rakshit, S.K.; de Carvalho, J.C.; Soccol, C.R. In Vitro Probiotic Properties and DNA Protection Activity of Yeast and Lactic Acid Bacteria Isolated from A Honey-Based Kefir Beverage. Foods (Basel, Switzerland) 2019, 8 (10). https://doi.org/10.3390/foods8100485.

32. Hajmeer, M.; Ceylan, E.; Marsden, J.L.; Fung, D.Y.C. Impact of Sodium Chloride on Escherichia Coli O157:H7 and Staphylococcus Aureus Analysed Using Transmission Electron Microscopy. Food Microbiol. 2006, 23 (5), 446-452. https://doi.org/10.1016/j.fm.2005.06.005. 